Solhjou Khah, F., Rybkowski, Z, Pentecost, A. R, Smith, J. P., and Muir, R. (2019). "Development and Testing of an Innovative Architectural Programming Simulation as a Precursor to Target Value Design" In: Proc. $27^{\text {th }}$ Annual Conference of the International. Group for Lean Construction (IGLC), González, V.A. (ed.), Dublin, Ireland, pp. 515-526. DOI: https://doi.org/10.24928/2019/0221. Available at: 〈www.iglc.net>.

\title{
DEVELOPMENT AND TESTING OF AN INNOVATIVE ARCHITECTURAL PROGRAMMING SIMULATION AS A PRECURSOR TO TARGET VALUE DESIGN
}

\author{
Fatemeh Solhjou Khah ${ }^{1}$, Zofia K. Rybkowski ${ }^{2}$, A. Ray Pentecost ${ }^{3}$, James P. Smith ${ }^{4}$, \\ and Robert Muir ${ }^{5}$
}

\begin{abstract}
More than half of international construction projects are underperforming. Poorly defined scope of work has been ranked as the one of the highest reasons for poor performance over which owners and construction stakeholders have control. An owner's requirements and expectations are specified during the programming phase of a project and these define a design's scope of work. One focus of Target Value Design (TVD) is making owner's value a primary driver of design by improving project definition during programming - thus optimizing the design phase. While the number of published research articles praising TVD has been increasing, there is a dearth of information regarding the application of architectural programming (AP) to Target Value Design exercises, which engage stakeholders in a design decision making process called Choosing by Advantages (CBA). CBA first requires identification of attributes that are of value to an owner. The purpose of this research was to explore the importance of architectural programming in helping to identify key attributes of value to an owner, and to report on a lean game designed and preliminarily validated by the authors to investigate the accuracy and perception of attribute identification through AP as represented by the game.
\end{abstract}

\section{KEYWORDS}

Target value design, value, design science, architectural programming, serious games and simulations

${ }^{1}$ Graduate Student, Department of Construction Science, Texas A\&M University, College Station, TX,77843 USA, +1 979-900-0654, ellie.solhjoukhah@ gmail.com

${ }^{2}$ Associate Professor, Department of Construction Science, Texas A\&M University, College Station, TX,77843, +1 979-845-4354, zrybkowski@tamu.edu (corresponding author)

${ }^{3}$ Professor of Practice, Department of Architecture, Texas A\&M University, College Station, TX, 77843, +1 979-845-7009, rpentecost@tamu.edu

${ }^{4}$ Assistant Professor, College of Engineering, Brigham Young University, Provo, UT 84602-8200, +1 801422-2023, james_smith@byu.edu

${ }^{5}$ Principal Faculty, Myers-Lawson School of Construction, Virginia Polytechnic Institute and State University, Blacksburg, VA, 24061,+1 540-231-9959, rmuirjr@vt.edu 


\section{INTRODUCTION}

Many reasons have been attributed to construction project cost overruns worldwide (Figure 1). The pre-eminent reason known as "material price escalation" refers to insecurity of an economy and inflation over which construction stakeholders have no control. However, poorly defined scope has been identified to be the second most influential reason for cost overruns in the construction industry, but the first over which the Owner, Architect, Engineer, and Contractor (OAEC) stakeholder team has control.

Architectural Programming (AP) is defined as the research and decision-making process that identifies the scope of work to be designed (WDBG 2016). It has been cited as a poorly implemented phase in the construction industry (Morêda Neto et al. 2016).

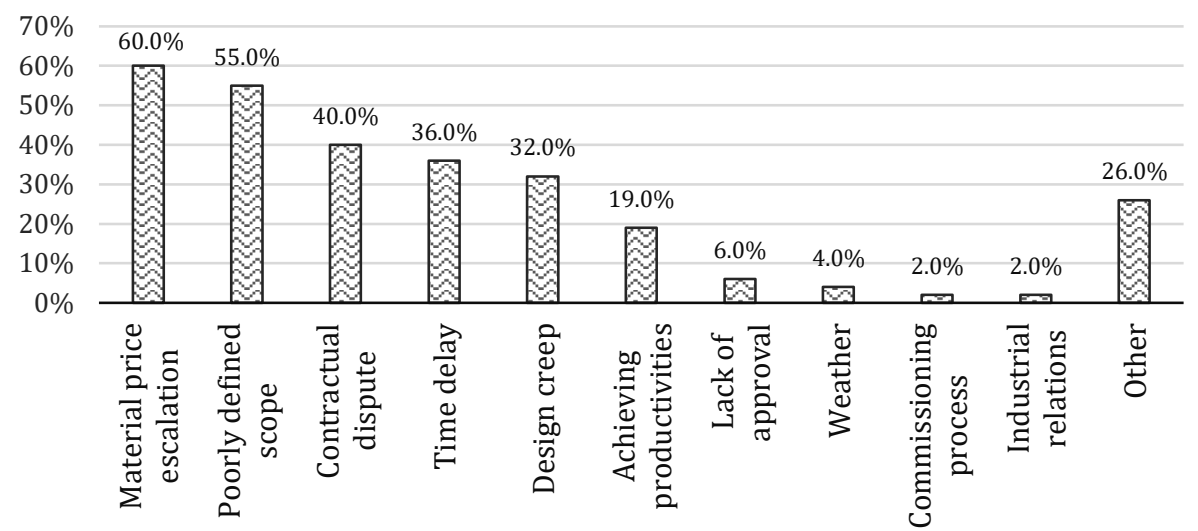

Figure 1. Reasons for cost overrun in construction projects worldwide, as of 2008. Adapted from PMI and KPMG (2013).

\section{LITERATURE REVIEW}

"Target Value Design (TVD) is a management strategy and known as a complex system, with stages including: Project definition (A), Design (B), and Construction (C) (Figure 2). It correlates closely with Lean thinking in design and construction" (p. 2, Zimina et al. 2012). TVD tools help stakeholders meet an allowable cost, while enhancing value, for a project owner, often saving a project as much as $15-20 \%$ on first cost (Ballard and Rybkowski 2009; Denerolle, S. 2013, Rybkowski et al. 2016).

To help educate participants about TVD, Rybkowski et al. (2016) developed a twophase estimating simulation to illustrate to participants the "Design/Develop Design/Detail Design" process (Figure 2, phase B) of TVD. However, "Project Definition/Business Planning/Plan Validation" (Figure 2, phase A) must precede the design process as it

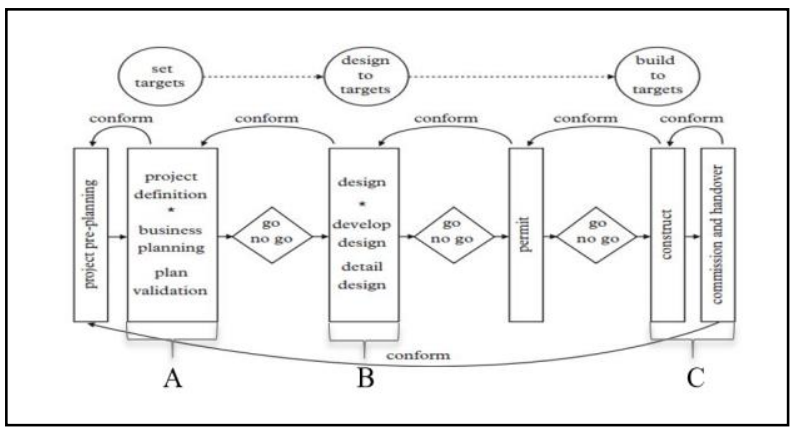
informs designers of what an owner values. A simulation to introduce participants to stage A was needed and did not yet exist. Filling this gap was the basis for this paper.

Figure 2. Target Value Design process scheme (Figure 4 in Zimina et al. 2012). 
For this study, seven architectural programming methods were identified including: Davis's Programming, Farbestian's Programming, McLaughlin's Programming, Kurtz's Programming, Moleski's Programming, White's Programming, and Peña's Programming (Sanoff 1992). For example, Peña's programming method addresses four primary elements including Function, Form, Economy, and Time. Peña's programming requires work sessions that gather all stakeholders involved in the project to explore 132 considerations covering many aspects of a project (Peña and Parshall 2001, Sanoff 2016).

In the construction industry, training and its advantages are underestimated, which leads to inadequate formal training activities (Kuykendall 2007). In a study conducted by Cox et al. (1998), it was found that companies, which invested in training practices, increased their productivity by $42 \%$. As with other skills, lean training is vital in establishing an advanced mindset and culture, which is critical to successful lean implementation (McGraw-Hill 2012). This training leads to the foundation for successful changes in an organization (Wan et al. 2008). Lean training is applicable in many forms, including lectures, presentations, hands-on games and activities, videos, and case studies. These approaches are effective when used separately, but they can also be adopted together for better overall performance. Serious games and simulations are some of the most efficient methods to demonstrate the advantages of lean tools and concepts (Kuriger et al. 2010). They differ from simple "gaming" in that the primary aim is educational-i.e. to learn through entertainment (Wouters et al 2007).

\section{PROBLEM STATEMENT}

This study seeks to address the need for construction stakeholders to develop an appreciation for systematic architectural programming at the start of a construction project during the early stages of TVD. The amount of information regarding the application of architectural programming to TVD is insufficient. In TVD, project definition is included as a separate upfront design step that should involve architectural programming. Therefore, the focus of this study is to design and test via proof of concept an innovative and functional Lean simulation in order to communicate the importance of architectural programming on value creation for the owner.

\section{RESEARCH OBJECTIVES}

The overall goal of this study is to develop and test a new lean simulation that introduces systematic architectural programming as a way to determine value for a building owner at the start of TVD. The objective of this specific research is to collect feedback after testing the simulation, and to use that feedback as a guide to improve future versions of the simulation. The ultimate aim is to help increase value of the built environment.

\section{PROPOSED METHODOLOGY}

This paper documents the exploratory, quantitative and qualitative development and testing of a lean architectural programming simulation at Texas A\&M University, Virginia Tech University, and Brigham Young University. In addition, a questionnaire was distributed to participants to evaluate the simulation's effectiveness. To the best of the 
authors' knowledge, there is no previous lean simulation which explores the impact of architectural programming. In this research, the authors developed a simulation to evaluate the importance of architectural programming (AP) by using an algorithmic manipulation of three floor plans to yield a compilation of 144 possibilities. By conducting a subsequent evaluation, research tested how systematic architectural programming (AP) might benefit the participants, who are about to embark on TVD exercises.

The Architectural Programming lean simulation was designed to investigate perceptions about the importance of AP. It was originally designed and tested at the College of Architecture at Texas A\&M University. It was pilot tested on graduate and undergraduate students, who were being prepared to enter construction related industries within the next one to five years. Students were affiliated with the departments of Construction Science, Architecture, and Civil Engineering. The Institution Review Board permitted testing to be performed in classrooms by the facilitators in the aforementioned departments at Texas A\&M University, and exact dates and times were set to conduct the simulation in classes. To administer the simulation, the facilitator read aloud instructions. At various points the facilitator clarified aspects of the game as needed, based on verbal questions from the participants, and provided written questionnaires to secure feedback from the students following play.

\section{Simulation Process:}

Before starting the game, instructions were delivered orally by the facilitator. Participants were divided into pairs of two members: one as an owner, and the other as an architect. Required material for this simulation included: Template for Scenarios (Figure 5), six Architectural Programming Scenarios which portrayed scenarios to define owner's expectations and requirements (Figure 6), Two 11" X 17" landscape format photocopies with 144 apartment layouts were provided for each pair with five variables including: Number of bedrooms, Ability/Disability, Solar Orientation, Open vs. Closed Kitchen, and Quality of Finishes (Figure 8). Each plan was given an identifier and three assigned potential quality of finishes (Low, Medium, High). The purpose of this lean game is for architect players to understand the difference of impact between not listening and listening carefully to an owner's needs before recommending to the owner appropriate diagrammatic apartment plan layouts with associated quality of finishes. The lean simulation was administrated in two rounds.

\section{Round I:}

Selected plan identifiers with associated quality of finishes were written on slips of paper and shuffled in a bowl for owners to draw (Figure 4). Owners memorized the drawn plan identifier with quality of finishes, and the architect was instructed to guess the plan identifier with quality of finishes. Architects were allowed to ask two yes or no questions pertinent to the given criteria on the blank "Template for Scenarios" in four minutes and owners were permitted respond to their questions based on the given information in the related Scenarios. At the end of the first round the architects were asked to guess what they believed was the owner's desired plan identifier and its quality of finishes. The facilitator then asked each architect to announce his or her guess. The results of the guess were collected onto a table drawn onto the room's white board. 


\section{Round II:}

In the second round, owners read their scenarios slowly to their architects. Architects were not allowed to ask any questions. But they were permitted to ask their owners to read their scenario again. Within six minutes, the architect players guessed the plan number and its quality of finishes. Participants' guesses were again recorded by the facilitator on the whiteboard table. The results for the two stages were compared. At the end of the game, Peña's Programming table was projected onto a screen in order to demonstrate how the lessons of the game can be applied to actual projects. In addition, a questionnaire was distributed to participants to collect feedback regarding their perceptions of the game (Figure 7).

This simulation is an effort to help the participants understand the importance of systematic architectural programming in meeting owner's requirements and expectations - i.e. what an owner deems to be of a greatest value. Moreover, the simulation indicates adverse effects of lack of communication between owners and architectural programmers on the outcomes of construction projects. An example of data collected on a whiteboard by the facilitator is shown (Table 1). All white board tables were photographed. These data, along with data from questionnaires completed by participants and all players were cumulatively inputted into excel and evaluated.

Table 1. Example of "Guess Table" drawn by facilitator on whiteboard

\begin{tabular}{|c|c|c|c|c|c|c|c|c|c|c|}
\hline & \multicolumn{10}{|c|}{ Team \# } \\
\hline RND I & \multicolumn{2}{|c|}{1} & \multicolumn{2}{|c|}{2} & & & \multicolumn{2}{|c|}{4} & \multicolumn{2}{|c|}{5} \\
\hline $\begin{array}{l}\text { Guessed } \\
\text { DWG \# and } \\
\text { Ouality of }\end{array}$ & \multicolumn{2}{|c|}{$\begin{array}{l}\text { E1-2 } \\
\text { Low }\end{array}$} & \multicolumn{2}{|c|}{$\begin{array}{c}\text { D4-2 } \\
\text { Medium }\end{array}$} & & & \multicolumn{2}{|c|}{$\begin{array}{c}\text { D2-1 } \\
\text { Medium }\end{array}$} & \multicolumn{2}{|c|}{$\begin{array}{c}\text { B4-1 } \\
\text { Medium }\end{array}$} \\
\hline & $\mathrm{Y}$ & (N) & (1) & $\mathrm{N}$ & $\mathrm{Y}$ & $(\mathbb{N})$ & $\mathrm{Y}$ & $(\mathrm{N})$ & $\mathrm{Y}$ & (N) \\
\hline \multicolumn{11}{|l|}{ RND II } \\
\hline $\begin{array}{l}\text { Guessed } \\
\text { DWG \# and } \\
\text { Quality of } \\
\text { Finishes }\end{array}$ & \multicolumn{2}{|c|}{$\begin{array}{c}\text { A2-2 } \\
\text { Medium }\end{array}$} & \multicolumn{2}{|c|}{$\begin{array}{c}\text { D4-2 } \\
\text { Medium }\end{array}$} & & & \multicolumn{2}{|c|}{$\begin{array}{l}\text { C4-1 } \\
\text { Low }\end{array}$} & \multicolumn{2}{|c|}{$\begin{array}{c}\text { D4-1 } \\
\text { Medium }\end{array}$} \\
\hline & (1) & $\mathrm{N}$ & (Y) & $\mathrm{N}$ & (Y) & $\mathrm{N}$ & (Y) & $\mathrm{N}$ & $\mathrm{Y}$ & $(\mathrm{N})$ \\
\hline
\end{tabular}

\section{RESEARCH LIMITATIONS}

While the outcome from these initial tests were promising, it must be acknowledged that the sample size was relatively small ( $N=136$, combining results from three universities); thus, the conclusions might not convincingly reflect the attributes of players from practice or industry. Also, the simulation does not take into consideration cultural differences among participants.

\section{RESULTS AND DATA ANALYSIS}

Results from the Architectural Programming (AP) Lean experiment from three universities (Texas A\&M, Virginia Tech, and Brigham Young; Table 2) indicate there was a marked decrease in the percentage of incorrect guesses from Round 1 (95.38\%) and 
Round $2(21.5 \%)$ - a decrease of $77.5 \%$. In other words, owner's requirements and expectations were not met during the first round but were largely met during the second round.

Table 2. Summarized pilot test results for AP lean simulation from three universities

\begin{tabular}{lcc}
\hline Round I & Percent of Correct Guesses & Percent of Incorrect Guesses \\
\hline TAMU & $4.54 \%$ & $95.65 \%$ \\
\hline VTech & $12.50 \%$ & $87.50 \%$ \\
\hline BYU & $2.94 \%$ & $97.06 \%$ \\
\hline Round I Total & $\mathbf{4 . 6 2 \%}$ & $\mathbf{9 5 . 3 8 \%}$ \\
\hline Round II & Percent of Correct Guesses & Percent of Incorrect Guesses \\
\hline TAMU & $78.26 \%$ & $21.74 \%$ \\
\hline VTech & $37.50 \%$ & $62.50 \% *$ \\
\hline BYU & $88.23 \%$ & $11.77 \%$ \\
\hline Round II Total & $\mathbf{7 8 . 5 0 \%}$ & $\mathbf{2 1 . 5 0 \%}$ \\
\hline
\end{tabular}

* Deviation in game implementation during Round II may be responsible for this number.

Various purposes for the AP lean simulation experiment were identified by participants. As Figure $\mathbf{3}$ shows, approximately $55 \%$ of players believed that "Communication" is the primary purpose of the simulation. Players perceived this simulation to be a useful tool to indicate the importance of communication and identifying owner's expectations, which ultimately outlines the importance of utilizing a comprehensive AP tool in the construction industry. Other evaluations were conducted to assess difficulty and levels of enjoyment while playing the Architectural Programming lean simulation. Approximately $77 \%$ of players believed that this simulation was "moderately easy" or "easy to understand", and $61 \%$ of players agreed

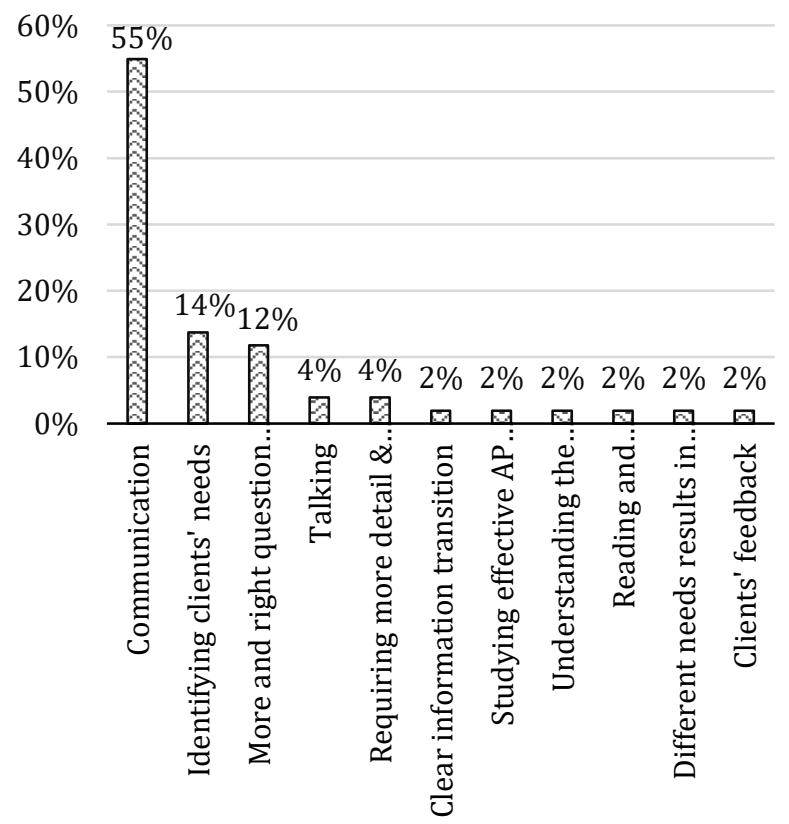

Figure 3. Results from questionnaire following play by Texas A\&M participants that this simulation was "very fun" or "extremely fun to play." These scores outline the convenience of this innovative lean simulation with respect to being played at organizations for the purpose of teaching the importance of AP in construction and other related fields. Participants' demographic data indicates that $86 \%$ of participants were male players, and $14 \%$ of them were female players. Approximately $87.5 \%$ of the players were undergraduate students, and $12.5 \%$ were graduate students. Players' academic majors were 
classified based on the degree they planned to earn within five years: $77.2 \%$ of participants were studying construction science, $10.3 \%$ architecture, $3.7 \%$ business, $2.2 \%$ civil engineering, $3.7 \%$ facilities management, $2.2 \%$ technology and engineering studies, and $0.7 \%$ product design. Typical feedback on how the AP lean simulation can be improved included: this simulation is a good game, provide more clear instruction, make it more challenging, provide more time, and permit more questions and guesses during Round $\mathrm{I}^{*}$. Outcomes of the AP lean simulation suggest that there was substantial alignment between an owner's expressed needs and an architect's design after the AP method was implemented e.g. 3 correct guesses in Round I vs. 51 correct guesses in Round II.

\section{DISCUSSION}

Although an in-depth discussion of Choosing by Advantages exercises (CBA; Suhr 1999) is beyond the scope of this paper, it is important to clarify that this simulation simply helps identify basic attributes that are critical to an owner. Target Value Design typically engages participants in CBA, which encourages stakeholders to brainstorm and then subject to criterion analysis multiple alternatives embodying these attributes (Arroyo et al. 2013; Schöttle et al. 2007). In other words, while there are many ways to design a twobedroom home, the designer needs to first recognize an owner wants a two-bedroom home, for example. Architectural programming helps identify critical attributes of value to an owner.

The AP lean simulation was developed as an attempt to communicate to OAEC (Owner, Architecture, Engineering, and Construction) stakeholders the importance of reliable architectural programming methods (AP) on OAEC projects. Preliminary feedback from simulation participants indicates that this simulation can be applied to real-world scenarios. While studies have been conducted on TVD in the fields of Lean Construction and Architectural Programming individually, there are few publications that address both simultaneously. The aim of this research is to integrate lean strategies and AP components to fill this gap. Indeed, these methods can both coexist and complement one other.

\section{CONCLUSION}

Project success has been defined by two key factors including managing costs to achieve efficiencies, and creating and enhancing value (Venkataraman and Pinto 2011). Lean Construction strategies can be applied in order to create and improve values in construction projects. However, 53\% of construction projects are underperforming overall (KPMG 2015). Poorly defined scope of work by OAEC stakeholders has been identified as the most frequent reason for project cost overruns. By improving the architectural programming stage of a project, stakeholders can improve scope of work related to owners, meet their expectations and requirements, and ultimately, increase the probability of project success. This paper suggests exploring ways to integrate lean strategies with architectural programming methods to fill a gap that synergistically addresses the needs of owners, architects, engineers, and contractors when embarking on TVD. The intent of this research

\footnotetext{
* The authors believe this feedback may reflect a misunderstanding of some participants of the purpose of the simulation.
} 
was to develop and test an innovative simulation to effectively highlight the value of architectural programming and its associated long-term benefits, thus helping to reduce cost overruns and increase project success among OAEC stakeholders. After playing the Architectural Programming simulation, participants indicated they understood the importance of architectural programming in the construction industry. Student participants in this study represented potential stakeholders in the construction industry, and it would be worthwhile for a future longitudinal research project to explore whether their understanding endures or is transformed as the student participants pursue careers following graduation.

\begin{tabular}{|c|c|}
\hline C4-1 (Low) & E3-1(High) \\
\hline D4-2 (Medium) & B3-2 (Low) \\
\hline D3-1 (Medium) & A2-2 (Medium) \\
\hline
\end{tabular}

Figure 4 (above). Slips of paper

(To be drawn by owners out of the bowl).

Figure 5 (right). Template for Scenarios (To be given to architects only).

Figure 6 (below left). Scenarios (To be given to owners only).

Figure 7 (below right). Feedback Questionnaire (To be given to all participants).

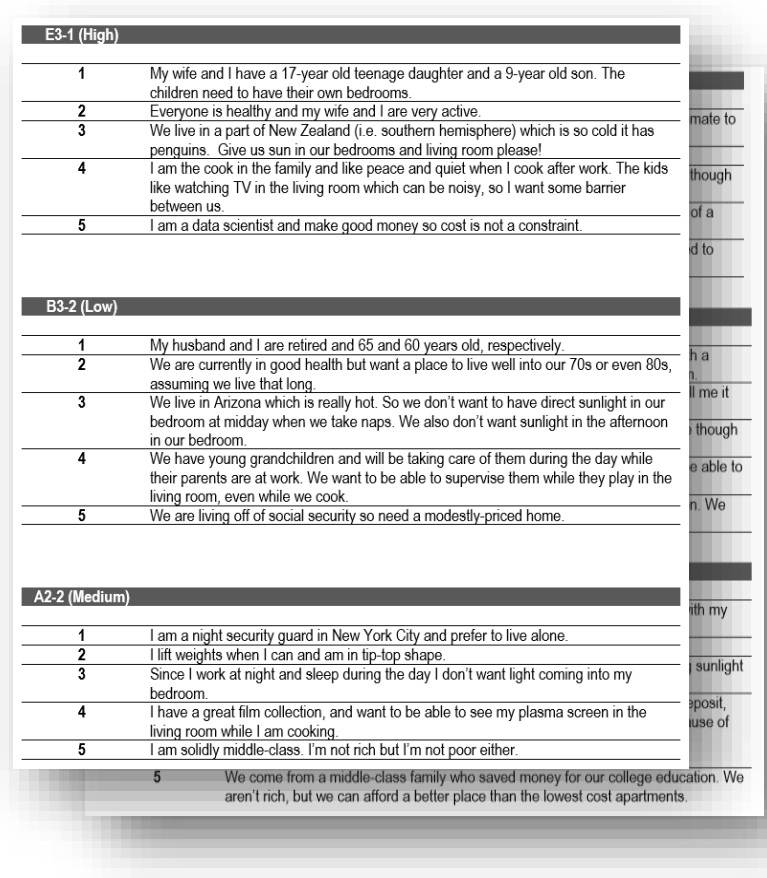

$\begin{aligned} & \text { Template for } \\
& \text { scenarios }\end{aligned}$
\begin{tabular}{|l|c|c|}
\hline Variables & $\begin{array}{c}\text { RND I } \\
\text { (Pick 2Variables to ask) }\end{array}$ & RND II \\
\hline 1 \# of bedrooms & & \\
\hline Ability / Disability & & \\
\hline Solar Orientation & & \\
\hline Open vs. closed kichen & & \\
\hline Cost of Finishes & & \\
\hline
\end{tabular}

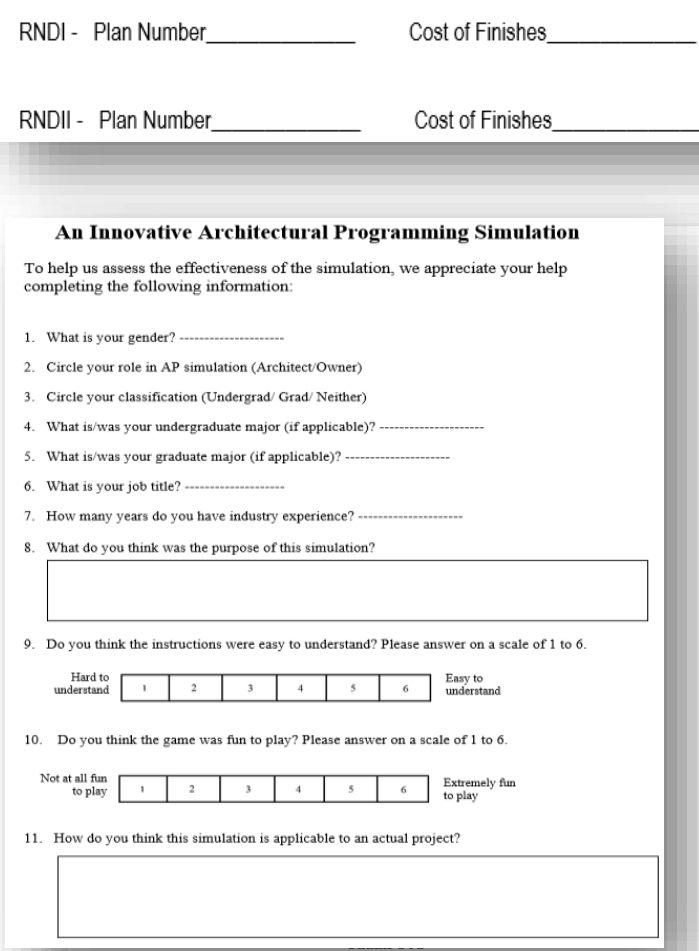




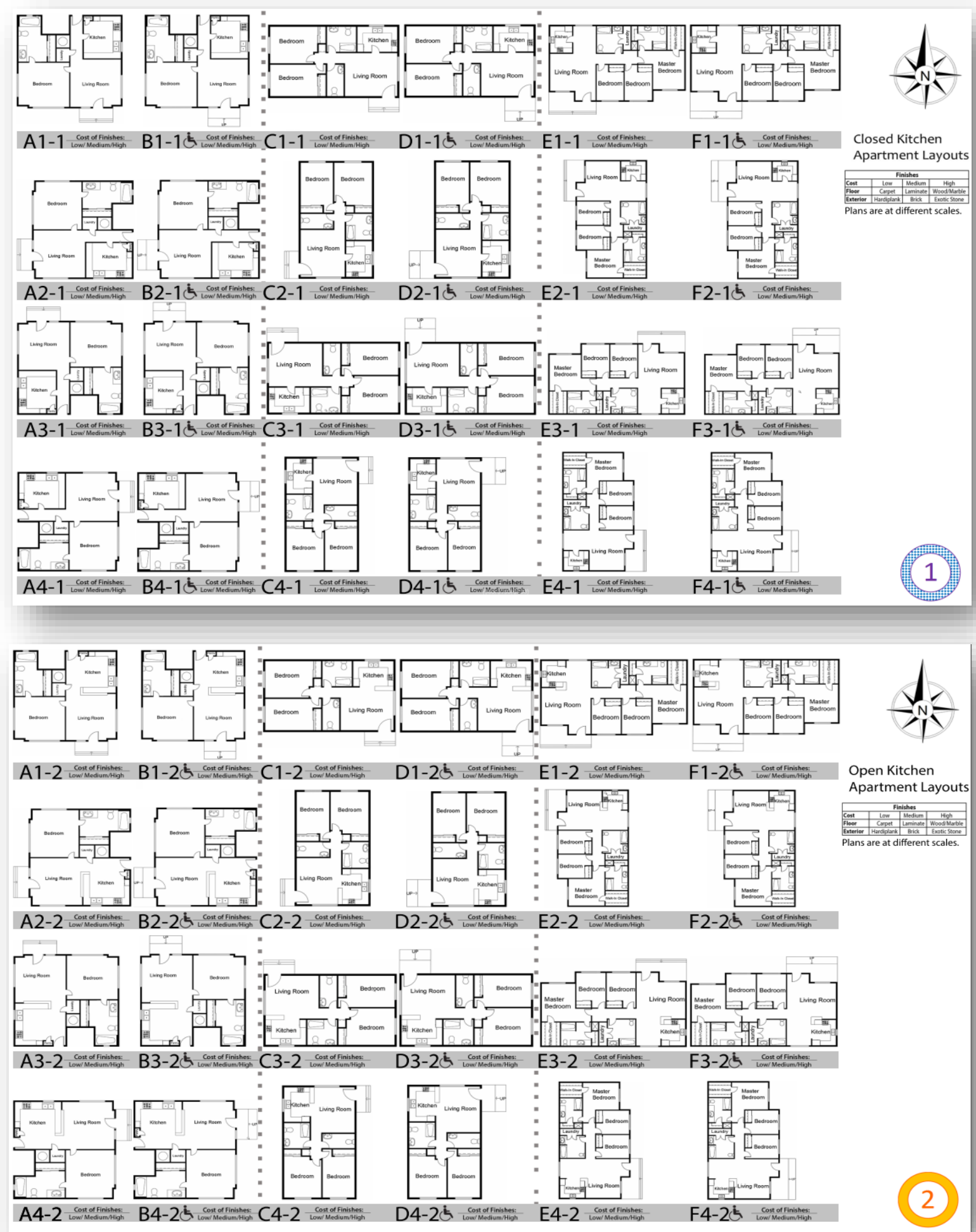

Figure 8. AP Simulation Materials: Architects must guess which of 144 floor plans best fulfill the owner's values (to be given to both owners and architects).

Sheets were numbered in color to clarify to players that the two sheets differ. 


\section{REFERENCE}

Arroyo, P., Tommelein, I. D., and Ballard, G. (2013). "Using Choosing by Advantages to select ceiling tile from a global sustainable perspective," Proceedings of the $21^{\text {st }}$

Annual Conference of the International Group for Lean Construction, July, Fortaleza, Brazil, 309-318.

Ballard, G., and Rybkowski, Z. K. (2009). "Overcoming the hurdle of first cost: A case study in target value design," The 2009 Construction Research Congress, Constr. Inst. of ASCE, Seattle, WA, 10 pp.

Cox, Robert F., R. Raymond Issa, and Heidi Collins. (1999). "Determining the Quantitative Return on Investment (ROI) of Craft Training." Report to the National center for Construction Education and Research, University of Florida, FL.

Denerolle, S. (2013). Technical Report: The application of Target Value Design to the design phase of 3 hospital projects. P2SL:Project Production Systems Laboratory, Berkeley, CA.

KPMG. (2015). "Percentage of construction projects underperforming in FY 2014, by sector." Statista - The Statistics Portal $<$ https://www.statista.com/statistics/526690/percentage-of-construction-projectsunderperforming-by-sector/> (Oct. 2, 2018).

Kuriger, G. W., Wan, H. D., Mirehei, S. M., Tamma, S., \& Chen, F. F. (2010). "A webbased lean simulation game for office operations: training the other side of a lean enterprise." Simulation \& Gaming, 41(4), 487-510.

Kuykendall C. J (2007). "Key Factors Affecting Labor Productivity in the Construction Industry," thesis, presented to University of Florida at Gainesville, FL, in partial fulfillment of the requirements for the degree of Master of Science.

Mc-Graw Hill Construction (2012). Construction Industry Workforce Shortages: Role of certifications, Training and Green jobs in filling the gaps smart market report. Bedford, MA.

Morêda Neto, H., Costa, D., and Thomas, L. (2016). "Target Value Design Approach for Real Estate Development." 24th Annual Conference on Lean Construction, The International Group for Lean Construction, (2016), Boston, MA, 63-72.

PMI and KPMG. (2013). "Reasons for cost overrun in construction projects worldwide, as of 2008." In Statista - The Statistics Portal $<$ https://www.statista.com/statistics/526875/reasons-for-cost-overruns-in-constructionprojects/> (Oct. 2, 2018).

Peña, W. M. and Parshall, S. A. (2001). Problem-Seeking: An Architectural Programming Primer, $4^{\text {th }}$ Ed., Wiley, New York, 224 pp.

Rybkowski, Z. K., Munankami, M., Shepley, M. M., and Fernández-Solis, J. L. (2016). "Development and testing of a lean simulation to illustrate key principles of Target Value Design: A first run study." Proceedings of the $24^{\text {th }}$ Annual Conference for the International Group for Lean Construction; July 20-22, 2016: Boston, MA, Sect. 4, $133-142$.

Sanoff, H. (1992). Integrating Programming, Evaluation and Participation in Design: A Theory $Z$ approach, Aldershot (Angleterre), Routledge, Brookfield (É.-U.), Avebury, England. 
Sanoff, H. (2016). Integrating Programming, Evaluation and Participation in Design (Routledge Revivals): A Theory Z Approach, Routledge, New York, NY.

Schöttle, A., Arroyo, P., and Haas Georgiev, C. (2017). "Applying Choosing by Advantages in the Public Tendering Procedure," Proceedings of the 25th Annual Conference of the International Group for Lean Construction, Heraklion, Greece, 4552.

Suhr, J. (1999). The Choosing By Advantages Decision Making System, Greenwood Publishing Group, Quorum, Westport, CT, 293 pp.

Venkataraman, R. R., \& Pinto, J. K. (2011). "Cost and value management in projects." John Wiley \& Sons.

Wan, H., Chen, F. F., \& Saygin, C. (2008). "Simulation and training for lean implementation using web-based technology." Int. Journal of Services Operations and Informatics, 3, 1-14.

Whole Building Deign Guide. (2018). <wbdg.org/design-disciplines/architecturalprogramming> (Oct. 10, 2018).

Wouters, P., Tabbers. H. K., and Paas, F. (2007). "Interactivity in video-based models," Educational Psychology Review, 327-342.

Zimina, D., Ballard, G., and Pasquire, C. (2012). "Target value design: using collaboration and a lean approach to reduce construction cost." Construction Management and Economics, 30(5), 383-398. 
Solhjou Khah, F., Rybkowski, Z, Pentecost, A. R, Smith, J. P., and Muir, R.

526

Proceedings IGLC - 27, July 2019, Dublin, Ireland 